\title{
Avoidance threshold to oil water soluble fraction by a juvenile marine teleost fish
}

\author{
Claireaux Guy ${ }^{1,{ }^{*}}$, Quéau Pierre ${ }^{1}$, Marras Stefano ${ }^{2}$, Floch Stéphane ${ }^{3}$, Farrell Anthony P. ${ }^{4}$, \\ Nicolas-Kopec Annabelle ${ }^{5}$, Lemaire Philippe ${ }^{6}$, Domenici Paolo ${ }^{2}$
}

${ }^{1}$ Université de Bretagne Occidentale, Laboratoire des Sciences de l'Environnement Marin (UMR 6539); PFOM-ARN, Centre Ifremer de Bretagne, Plouzané, France

2 Istituto per l'Ambiente Marino Costiero, Consiglio Nazionale delle Ricerche, Località Sa Mardini;

Torregrande, Oristano , Italy

${ }^{3}$ Centre de Documentation, de Recherche et d'Expérimentations sur les pollutions accidentelles des eaux; Brest, France

${ }^{4}$ Department of Zoology and Faculty of Land and Food Systems; University of British Columbia; Vancouver ,Canada

${ }^{5}$ The International Tanker Owners Pollution Federation Limited; London, United Kingdom

${ }^{6}$ Total Fluides, Paris La Défense-Cedex,France

*Corresponding author : Guy Claireaux, email address : guy.claireaux@univ-brest.fr

\begin{abstract}
:
When oil spills occur, behavior is the first line of defense for a fish to avoid being contaminated. Here, we determined the avoidance threshold of the European seabass (Dicentrarchus labrax) to the watersoluble fraction (WSF) of oil using a dual flow choice box. Our experiment revealed that a plume of 20\%-diluted WSF (total PAH concentration: $8.54 \mu \mathrm{g} \mathrm{L}-1$ ) triggered a significant avoidance response that was detected within 7.5 minutes of introducing WSF-contaminated water in the experimental set-up. However, the ecological relevance of seabass capacity to detect and avoid WSF remains to be established. In the short term, such response is indeed liable to reduce sea bass contact time with oilcontaminated water and thus preserve their functional integrity. In the long term, however, this may contribute to displace a population into a possibly less auspicious environment, with very similar consequences than contaminant exposure i.e., disturbed population dynamics and demography.
\end{abstract}

Keywords : Fish, Oil, Behavior, Avoidance reaction, WSF 


\section{INTRODUCTION}

With the steady rise in worldwide demand for oil, offshore drilling projects are expanding to more extreme and demanding environments. As a result, the probability for accidents during exploration, transport or production activities is increasing. This trend is of great concern not only for the potential socio-economic consequences of accidental oil releases, but also for the threat they pose to marine ecosystems (IEA 2010; Li et al., 2016).

The fate of a plume of petroleum hydrocarbons released at sea depends on a number of factors which include (i) the type of accident (e.g. blow-out, shipwreck, ballast water discharge); (ii) the nature of the product released (e.g. refinery residuum, heavy oil, light fuel); (iii) the hydrographic conditions (e.g. temperature, salinity, water column stratification, tide and current patterns); and (iv) climate (e.g. light, wind, wave) (Incardona et al., 2014). Likewise, the ecological impact of this plume will vary with the toxicity of the spilled product, the characteristics of its components (e.g., solubility, density, vapor pressure, biodegradability), the exposure quantity, the living organisms considered, their life stage, their habitat, their mobility, their feeding mode and the presence of other environmental stressors (Craig and Crowder, 2000). As recently reviewed by Chang et al., (2014), all these factors have been investigated to varying extents (Beyer et al., 2016). However, the contribution of avoidance behavior to modulating the impact of spilled petroleum hydrocarbons, particularly to the water-soluble fraction (WSF), has been seldom addressed.

Arguably, behavior responses represent the first line of defense for an organism confronted with unfavorable conditions. Indeed, avoidance in fish is well documented in response to sound (Knudsen et al., 1997; Maes et al., 2004), predator odor (Berejikian et al., 1999; Dixson et al., 2010) chemicals (Exley, 2000; Summerfelt and Lewis, 1967) and hypoxia

This article is protected by copyright. All rights reserved 
(Wannamaker and Rice, 2000). Avoidance is a complex integrative process involving the perception of sensory cues and the neural process which leads to the spatial representation of environmental landmarks and gradients (Chan et al., 2012). However, current inaccurate comprehension of this broad sensory signal integration prevents proper attribution of causalities, making it difficult, for instance, to separate olfactory toxicity from other forms of toxicity (Tierney et al., 2010). The difficulty in identifying causalities has been illustrated by previous works which showed, for instance, that benthic fish species will avoid heavily oiled sediments but do not necessarily avoid lightly oiled sediments that they can also detect (Hinkle-Conn et al., 1998; Moles et al., 1994). Regardless, the ability to detect and avoid petroleum hydrocarbons is a crucial modulating factor of the impact of an oil spill upon fish performance and activities and, therefore, its understanding is central to planning countermeasures to reduce the consequences of an oil spill, particularly in the context of Spill Impact Mitigation Assessment (Robinson et al., 2017). This information is also essential to the proper delimitation and protection of high-risk areas and their associated biological resources.

Consequently, the present work determined the avoidance threshold to the WSF of oil for the European seabass (Dicentrarchus labrax), a commercially important species which is typical of fish communities in Western and Mediterranean Europe. To reach this objective, a twocurrent choice flume was used. This flume allowed fish to select between an unpolluted water flow and a water flow contaminated with various levels of WSF of crude Arabian light. Fish movements between the two water flows were monitored using video recording.

This article is protected by copyright. All rights reserved 


\section{MATERIALS AND METHODS}

Animals

Juvenile European seabass (Dicentrarchus labrax; age: 1.5 years) used in this experiment were drawn from a population reared at Ifremer aquaculture facility (Brest, France) since 3 days post hatch. These larvae were initially obtained from a local fish farm (Aquastream, Lorient, France) and were reared in tanks supplied with open flow and filtered sea water. During that period, light and water conditions varied seasonally (temperature $10-19^{\circ} \mathrm{C}$; salinity $30-32 \%$; $\mathrm{pH}$ 8.0-8.2; oxygen $>90 \%$ air saturation). Two weeks before experiment started, fish were transported across town to the Centre of Documentation, Research and Experimentation on Accidental Water Pollution (CEDRE, Brest, France) and were placed in a $500 \mathrm{~L}$ tank supplied with open flow aerated and filtered seawater at a temperature of $20^{\circ} \mathrm{C}$. Fish were fed twice a week with commercial dry pellets (Neo Start; Le Gouessant, Lamballe, France). At the time of the experiments fish total length and mass were $5.57 \pm 0.36 \mathrm{~cm}$ and $2.86 \pm 0.47 \mathrm{~g}$, respectively $(\mathrm{N}=80)$.

\section{Experimental setup}

Fish were tested in a dual flow choice box with a clear Plexiglas working area of $40 \mathrm{~cm} \times$ $32 \mathrm{~cm} \times 15 \mathrm{~cm}$ (length $\times$ width $\times$ depth; Loligo Systems, Tjele, Denmark). This apparatus maintained two parallel water flows without mixing until the downstream exit. Fish were able to move freely across the two sides of the working area and freely enter either water flows, which allowed pair-wise choice experiments. Water flows $\left(1.5 \mathrm{~cm} \mathrm{~s}^{-1}\right)$ across the choice flume were generated using the hydraulic head of two $80 \mathrm{~L}$ columns situated upstream from the working area. These columns allowed the aeration of the incoming water as well as the dilution of WSFcontaminated water with clean sea water. The WSF dilution ratio was established by a set of

This article is protected by copyright. All rights reserved 
valves and flow meters situated upstream from the mixing columns and connected either to the clean seawater supply or to a tank containing the WSF-contaminated seawater. Allocation of WSF-polluted water to one side of the choice box was randomized. A video camera (Logitech, QuickCam Communicate STX) placed above the choice flume monitored fish movements.

A stock solution of WSF-contaminated water was prepared by mixing $3 \mathrm{~L}$ of crude oil

(crude Arabian light; CAL) with $2 \mathrm{~m}^{2}$ of natural seawater in a $2.5 \mathrm{~m}^{3}$ polyethylene tank. A submersible pump (MC450, Micro-Jet, NEWA, Sarrebourg, France) was placed at the bottom of that tank to allow homogenization. After 7 days, the homogenization pump was turned off, the solution left to settle for 2 hours and the supernatant removed by siphoning. The tank was then connected to the experimental set-up via a second pump (M7, Siebec, Saint-Egrève, France). Details on the chemical composition of the WSF-contaminated water (stock solution) are given in Table 1. Between trials the whole experimental set up was rinsed during $2 \mathrm{~h}$ with open flow seawater.

\section{Experimental protocol}

Experiments were conducted on 3-day fasted fish and three dilutions of the WSF stock solution, plus a control, were tested. Targeted dilutions of the stock solution were 3:10 (achieved 30.77\%; $\left.\mathrm{WSF}_{\text {high }}\right), 2: 10$ (18.18\%; $\left.\mathrm{WSF}_{\text {medium }}\right)$ and 1:10 (10.01\%; $\left.\mathrm{WSF}_{\text {low }}\right)$. Water contaminated with WSF was injected on the "contaminated side" of the choice flume while clean seawater entered the "control" side. During preliminary experiments, fish showed signs of stress when alone in the experimental arena (hyperventilation, stillness in a corner or along the side of the arena). During tests conducted with groups of up to 5 fish we found that above 2 individuals per group, no difference in distribution pattern and spontaneous activity level was detectable while the identification of the focal fish on the video recordings became progressively more difficult.

This article is protected by copyright. All rights reserved 
Thus, experimental trials were conducted using pairs of fish that were transferred in the middle of the choice box a minimum of $1 \mathrm{~h}$ before treated water was introduced into one of the water flows. During that acclimation period, fish, initially motionless, would progressively resume swimming activity and explore the whole arena. Note that fish were experimented only once. The preference for contaminated versus control water was tested after 5 min by measuring the proportion of time during the next 2.5 min a focal fish (randomly chosen within the pair) spent in the contaminated flow. Juvenile seabass are known to form schools in nature. Testing solitary fish would affect their natural behaviour. Therefore we used pairs of individuals in our experiments. Because schooling fish show homogenous behaviour, the use of a focal fish for analysis is common in schooling fish studies (Ward and Krause, 2001; Herbert-Read et al., 2011, Killen et al., 2012; Marras et al., 2015). Note that the focal fish did not carry any identification marks but was always easily differentiated during the video analysis. For each of the three WSF dilutions tested, a total of 20 trials were carried out i.e., 10 trials with treated water in either side (left and right) of the choice box to control for potential tank asymmetry. An additional 20 control trials were similarly performed using clean seawater on both sides of the choice flume. At the end of each trial, water samples (500 mL bottles filled to the top) were taken in triplicate at the end of each side of the flume and stored at $+6{ }^{\circ} \mathrm{C}$ for later analysis (within 2-3 days). Chemical analysis

Water samples were analyzed for PAH (alkylated and parents) according to the method described in Roy et al., (2005). Water samples were first submitted to a $24 \mathrm{~h}$ settling phase to separate particulate matter. Then, $150 \mu \mathrm{L}$ of a solution of five perdeuterated internal standards in acetonitrile (Naphthalene d8, Biphenyl d10, Phenanthrene d10, Chrysene d12, and Benzo[a]pyrene d12 at respective concentrations of 210, 110, 210, 40 and $40 \mu \mathrm{g} / \mathrm{mL}$, Sigma-

This article is protected by copyright. All rights reserved 
Aldrich, France) were diluted in $10 \mathrm{ml}$ of absolute methanol (Sigma-Aldrich, France) and the resulting solution was added to the liquid phase of the water samples. Using the stir bar sorptive extraction technique (SBSE-Stir bar coated with PDMS, Gerstel, USA) and thermal desorption coupled to capillary gas chromatography-mass spectrometry (Hewlett Packard, Palo Alto, CA, USA), PAH were extracted from the seawater and quantified (detection limit: $1 \mathrm{ng} / \mathrm{L}$ ).

\section{Data analysis and statistics}

Tank asymmetry was tested using t-tests for treated water in the left or the right side of the choice flume. Avoidance behaviour was tested using a one sample t-test against the null expectation of 0.5 for the mean proportion of time spent in the treated side of the choice box (i.e. $50 \%$ of the time in either sides of the tank, based on a random choice). For the control group, the mean proportion of time spent in a randomly chosen side of the choice-box was used. In case of non-normal distribution (assessed using D'Agostino test), a Wilcoxon signed rank test was used. The mean time spent in the side of the choice box containing treated water at different dilutions or control water were then compared among the control seawater and the three WSF concentrations using a one-factor non- parametric ANOVA (i.e. Kruskal-Wallis test) and a posthoc Dunn's multiple comparison test.

\section{RESULTS}

Thorough rinsing of the experimental set up ensured that all trials were conducted under the same contamination free, conditions. This is illustrated in Table 1 where, under control conditions, most PAH compounds were at concentration below detection limit. Exception to this were acenaphthylene, chrysene, benzo [b+k] fluoranthene and benzo[e]pyrene for which we have no satisfying explanation. It must be noticed however that the sea water used for this experiment was pump from the bay of Brest and that a low level background contamination is possible. For

This article is protected by copyright. All rights reserved 
each treatment, trials with contaminated water in the left and right sides of the choice flume were pooled after testing for differences (t-tests, $\mathrm{p}>0.05$ for all treatments). Nominal dilutions of WSF stock solution produced nearly proportional changes in initial PAH concentrations (Table 1). Measured total PAH concentrations were 6.6, 3748.2, 8542.4, 14935.7 and $81045.4 \mathrm{ng} \mathrm{L}^{-1}$ for the control, $\mathrm{WSF}_{\text {low, }}, \mathrm{WSF}_{\text {medium, }} \mathrm{WSF}_{\text {high }}$ and $\mathrm{WSF}_{\text {stock }}$ respectively. Each treatment showed a normal distribution of the data, except for the $\mathrm{WSF}_{\text {medium }}$ (D'Agostino test, $\mathrm{p}<0.05$ ).

The proportion of time spent by the focal fish on the treated side of the choice box in two out of four conditions did not differ from the null expectation of 0.5 (Fig.2; randomly chosen control side, $\mathrm{t}=1.961, \mathrm{df}=19, \mathrm{p}>0.05$; and $\left.\mathrm{WSF}_{\text {low }} \mathrm{t}=0.9055, \mathrm{df}=19, \mathrm{p}>0.05\right)$. In contrast, for the two higher WSF concentrations, $\mathrm{WSF}_{\text {medium }}$ and $\mathrm{WSF}_{\text {high, }}$, fish spent significantly less time than the null expectation of 0.5 in the water flow containing the contaminated water (Fig.2; Wilcoxon test, $\mathrm{df}=19, \mathrm{p}<0.05$; t-test and $\mathrm{t}=2.097, \mathrm{df}=19, \mathrm{p}<0.05$, respectively).

The Kruskal-Wallis test revealed a significant difference among the four treatments (Fig. 2; $\mathrm{p}<0.05)$. The post-hoc test showed significant differences in the control versus the $\mathrm{WSF}_{\text {medium }}$ and in the control versus $\mathrm{WSF}_{\text {high }}$ treatments (Dunn's test, both $\mathrm{p}<0.05$ ), while no difference was found between the control and the WSF low treatment (Dunn's test, $\mathrm{p}>0.05$ ).

\section{DISCUSSION}

It is generally assumed that avoidance reaction to oil-polluted water confers resilience against contamination, as it contributes to reducing the duration and severity of the exposition and to minimizing consequences upon fish physiological and behavioral performance and repertoire (Blaxter and Hallers-Tjabbes, 1992). This assumption is, however, not always valid and previous works show contradictory results (Bøhle, 1986; Folmar, 1976; Maynard and Weber, 1981; Moles et al., 1994; Morrow, 1973; Rice, 1973; Sprague and Drury, 1969), possibly

This article is protected by copyright. All rights reserved 
due to the challenge in acquiring repeatable and quantifiable information (Kane et al., 2005). The present work used a dual flow swim flume to identify, in the European seabass, the avoidance threshold to the WSF of oil. Our experiment revealed that a plume of 1:10 diluted WSFcontaminated water did not trigger a significant avoidance reaction in this species. On the other hand, dilutions of 2:10 and 3:10 quickly did.

The present study allowed full dissolution of the stock solution of WSF-contaminated water by preparing it 7 days ahead of the behavioral trials to account for the low water solubility and dissolution rate of some of the compounds and the evaporation of the others. As a result, measured polycyclic aromatic hydrocarbon (PAH) concentrations in that stock solution as well as in the various experimental dilutions were in line with reported values in similar experiments (Aas et al., 2000; Meier et al., 2010; Milinkovitch et al., 2011 and 2012; Sundt et al., 2012).

The neurosensory process that allows organisms to position themselves in their surroundings to take advantage of existing biotic and abiotic resources can be strained by dissolved contaminants as these molecules may interfere with natural stimuli or may act as stimuli themselves (Tierney, 2016). Therefore, understanding and predicting how fish sensory systems and behaviours are affected by human activity-related changes is crucial to ensuring proper understanding of the anthropogenic influences upon fish populations and proper repmediation and preservation strategies. However, previous works on avoidance behavior of fish exposed to WSF have produced contradictory results and, when observed, avoidance reaction sometimes occurred at concentrations generally considered unrealistic and lethally toxic (in the low mg L ${ }^{-1}$ range; Tierney, 2016). For instance, Folmar (1976) reported that rainbow trout (Oncorhynchus mykiss) was attracted to p-xylene at a concentration of $0.01 \mathrm{mg} \mathrm{L}^{-1}$ but avoided it at $0.1 \mathrm{mg} \mathrm{L}^{-1}$. Sprague and Drury (1969) showed that rainbow trout did not avoid phenol at a

This article is protected by copyright. All rights reserved 
near lethal concentration of $10 \mathrm{mg} \mathrm{L}^{-1}$. Rice (1973) found that avoidance of the water-soluble fraction of Prudhoe Bay crude oil by pink salmon (Oncorhynchus gorbuscha) fry varied with developmental stage, temperature and salinity. Maynard and Weber (1981) showed that presmolt Coho salmon (Oncorhynchus kisutch) avoided a mixture of monocyclic aromatic hydrocarbons at concentrations of 3-4 $\mathrm{mg} \mathrm{L}^{-1}$, while smolting Coho salmon avoided concentrations of less than $2 \mathrm{mg} \mathrm{L}^{-1}$. These authors also individually tested three components (benzene, toluene and o-xylene) of the mixture in pre-smolt salmon. Each component was avoided at a lower concentration than when compared with the total hydrocarbon concentration of the mixture.

All the same, it is believed that even though concentrations of contaminants in the environment are typically low, they can still elicit behavioral responses (Tierney et al., 2010). For example, some odorant molecules can trigger responses in fish olfactory system at a concentration of $10^{-9} \mathrm{M}$ (Hara, 1992). However, very few studies (e.g., Bøhle, 1986 in Gadus morhua) actually report avoidance reactions to oil compounds at concentrations in the $\mu \mathrm{g} \mathrm{L}{ }^{-1}$ range. The present work increases the number of these reports by revealing that seabass can detect, and avoid, contaminated water with a total sum of PAH concentrations in the range 3-15 $\mu g \mathrm{~L}^{-1}$ (Table 1). This result also points out, at least in this species, that the reaction threshold to dissolved petroleum hydrocarbons is below reported toxic level (mg range; Mauduit et al., 2016) and that avoidance behavior therefore confers resilience against contamination (Blaxter and Hallers-Tjabbes, 1992). It must be noted, however, that acute toxic level in the $\mu \mathrm{g}$ range have been reported in other species e.g., Mager et al. (2014) in mahi-mahi (Coryphaena hippurus).

In fish, sensory neurons receive olfactory inputs directly from the aquatic environment, ensuring rapid information processing and response. Besides showing that sea bass behaviorally

This article is protected by copyright. All rights reserved 
responded to low levels of WSF, the current work demonstrated a rapid avoidance behavior i.e., within 7.5 min of introducing WSF in the choice flume. Such a short response time is remarkable if one considers that the water velocity in the $40-\mathrm{cm}$ long choice box was in the order of $1.5 \mathrm{~cm}$ $\mathrm{s}^{-1}$. It must be noted, however, that although the transition between the contaminated and clean water masses was sharp (insert Fig.1), some dilution inevitably occurred as the front travelled down the experimental arena. Additional information on response parameters such as responsiveness, latency, directionality, swimming speed and distance covered, that were not examined here, could be useful to fully characterized sea bass avoidance ability. Also, it would be interesting to investigate the relationship possibly linking animals’ personality and physiology to behavioral and kinematic parameters of their avoidance response. Behavioral trait variation has been shown to have high ecological significance in fishes, and links between energy metabolism, behavior and performance have been suggested (Mittelbach et al., 2014: Metcalfe et al., 2016).

Although we demonstrated that the European sea bass avoided relatively low levels of WSF contaminated water, the ecological relevance of this result remains to be established. In the short term, such response is liable to reduce sea bass contact time with oil-contaminated water and thus preserve their functional integrity. In the long term, however, this seemingly favorable “overt” reaction may have unpredictable "covert” consequences. By displacing a fish population into a possibly less auspicious environment with regards to abiotic and biotic conditions, an oilcontaminated water body may actually affect their ability to avoid predators, to feed or to allocate sufficient energy to growth and reproduction. Over time, this is likely to end up with very similar consequences as contaminant exposure with, in the long run, consequences such as disturbed population dynamics and demography (Fodrie et al., 2014; Kasumyan 2001).

This article is protected by copyright. All rights reserved 
Acknowledgment-The present project was funded through ITOPF 2012 R\&D award. It also received the financial support of Total-Fluides. Authors would also like to thank J. Moriceau for his help with analyzing the videos, N. Le Bayon for his technical assistance and D. Claireaux for creating Figure 1. A. P. Farrell holds a Canada Research Chair.

Data availability—Data, associated metadata, and calculation tools are available from the corresponding author (guy.claireaux@univ-brest.fr).

Published online XXXX 2017 in Wiley Online Library (www.wileyonlinelibrary.com).

DOI: 10.1002/etc.xxxx

This article is protected by copyright. All rights reserved 


\section{REFERENCES}

Aas E, Baussant T, Balk L, Liewenborg B, Andersen OK. 2000. PAH metabolites in bile, cytochrome P4501A and DNA adducts as environmental risk parameters for chronic oil exposure: A laboratory experiment with Atlantic cod. Aquat Toxicol 51: 241-258.

Berejikian BA, Smith RJF, Tezak EP, Schroder SL, Knudsen CM. 1999. Chemical alarm signals and complex hatchery rearing habitats affect antipredator behavior and survival of chinook salmon (Oncorhynchus tshawytscha) juveniles. Can J Fish Aquat Sci 56: 830-838.

Beyer J, Trannum HC, Bakke T, Hodson PV, Collier TK. 2016. Environmental effects of the Deepwater Horizon oil spill: A review. Mar Poll Bull 110: 28-51.

Blaxter JHS, Hallers-Tjabbes CCT. 1992. The effect of pollutants on sensory systems and behaviour of aquatic animals. Neth J Aquat Ecol 26: 43-58.

Bøhle B. 1986. Avoidance of petroleum hydrocarbons by the cod (Gadus morhua). Fiskeddir Skr. 18: 97-112.

Chan E, Baumann O, Bellgrove MA, Mattingley JB. 2012. From objects to landmarks: the function of visual location information in spatial navigation. Frontiers in Psychology 3: 304. doi: 10.3389/fpsyg.2012.00304

Chang SE, Stone J, Demes K, Piscitelli M. 2014. Consequences of oil spills: a review and framework for informing planning. Ecology and Society 19: 26.

Craig JK, Crowder LB. 2000. Factors influencing habitat selection in fishes with a review of marsh ecosystems. In: Weinstein MP, Kreeger DA, eds, Concepts and controversies in tidal marsh ecology. Kluwer Academic Publishers, Dordrecht, The Netherlands, pp 241-266.

Dixson DL, Munday PL, Jones GP. 2010. Ocean acidification disrupts the innate ability of fish to detect predator olfactory cues. Ecology Letters 13: 68-75.

This article is protected by copyright. All rights reserved 
Exley C. 2000. Avoidance of aluminum by rainbow trout. Envir Tox Chem 19: 933-939.

Fodrie FJ, Able KW, Galvez F, Heck KLJ, Jensen OP, Lopez-Duarte PC, Martin CW, Turner

RE, Whitehead A. 2014. Integrating organismal and population responses of estuarine fishes in

Macondo spill research. BioScience 64: 778-788.

Folmar LC. 1976. Overt avoidance reaction of rainbow trout fry to nine herbicides. Bull Envir Contam Toxicol 15: 509-514.

Herbert-Read JE, Perna A, Mann RP, Schaerf TM, Sumpter DJT, Ward AJW. 2011. Inferring the rules of interaction of shoaling fish. PNAS 108: 18726-18731.

Hinkle-Conn C, Fleeger JW, Gregg JC, Carman KR. 1998. The effect of sediment-bound polycyclic aromatic hydrocarbons on feeding behavior in juvenile spot (leiostomus xanthurus Lacépède: Pisces). J Exp Mar Biol Ecol 227: 113-132.

IEA. 2010. World Energy Outlook 2010. Paris, France.

Incardona JP, Gardner LD, Linbo TL, Swarts TL, Esbaugh AJ, Mager EM, Stieglitz JD, French BL, Labenia JS, Laetz CA et al. . 2014. Deepwater Horizon crude oil toxicity to the developing hearts of large predatory pelagic fish. PNAS 111: E1510-E1518.

Robinson H, Gardiner W, Wenning RJ, Rempel-Hester MA. 2017. Spill impact mitigation assessment framework for oil spill response planning in the Arctic environment, International Oil Spill Conference Proceedings 2017: 1325-1344. https://doi.org/10.7901/2169-33582017.1.1325.

Kane AS, Salierno JD, Brewer SK. 2005. Fish models in behavioral toxicology: Automated techniques, updates and perspectives. In: Ostrander GK, ed, Methods in Aquatic Toxicology. Lewis Publishers, Boca Raton, FL, USA, pp 559-590.

This article is protected by copyright. All rights reserved 
Kasumyan AO. 2001. Effects of chemical pollutants on foraging behavior and sensitivity of fish to food stimuli. J Ichthyol 41: 76-87.

Killen SS, Marras S, Steffensen JF, McKenzie DJ. .2012. Aerobic capacity influences the spatial position of individuals within fish schools Proc. R. Soc. B 279: 357-364.

Knudsen FR, Schreck CB, Knapp SM, Enger PS, Sand O. 1997. Infrasound produces flight and avoidance responses in Pacific juvenile salmonids. J Fish Biol 51: 824-829.

Li P, Cai Q, Lin W, Chen B, Zhang B. 2016. Offshore oil spill response practices and emerging challenges. Mar Poll Bull 110: 6-27.

Maes J, Turnpenny AWH, Lamber DR, Nedwell JR, Parmentiers A, Ollevier F. 2004. Field evaluation of a sound system to reduce estuarine fish intake rates at a power plant cooling water inlet. J Fish Biol 64: 938-946.

Mager EM, Esbaugh AJ, Stieglitz JD, Hoenig R, Bodinier C, Incardona JP, Scholz NL, Benetti DD, Grosell M. 2014. Acute embryonic or juvenile exposure to Deepwater Horizon crude oil impairs the swimming performance of mahi-mahi (Coryphaena hippurus). Environ Sci Technol 48: 7053-7061.

Marras S, Killen SS, Lindström J, McKenzie DJ, Steffensen JF, Domenici P. 2014. Fish swimming in schools save energy regardless of their spatial position. Behav. Ecol. Sociobiol. 69: 219-226.

Mauduit F, Domenici P, Farrell AP, Lacroix C, Le Floch S, Lemaire P, Nicolas-Kopec A, Whittington M, Zambonino-Infante JL, Claireaux G. 2016. Assessing chronic fish health: an application to a case of an acute exposure to chemically treated crude oil. Aquat Toxicol 178: 197-208.

This article is protected by copyright. All rights reserved 
Maynard DJ, Weber DD. 1981. Avoidance reactions of juvenile coho salmon (Oncorhynchus kisutch) to monocyclic aromatics. Can J Fish Aquatic Sci 38: 772-778.

Meier S, Morton HC, Nyhammer G, Grøsvik BE, Makhotin V, Geffen A, Boitsov S, Kvestad KA, Bohne-Kjersem A, Goksøyr A, Folkvord A, Klungsøyr J, Svardal A. 2010. Development of Atlantic cod (Gadus morhua) exposed to produced water during early life stages: Effects on embryos, larvae, and juvenile fish. Mar Envir Res 70: 383-394.

Metcalfe NB, Van Leeuwen TE, Killen SS. 2016. Does individual variation in metabolic phenotype predict fish behaviour and performance? J Fish Biol 88: 298-321.

Mittelbach GG, Ballew NG, Kjelvik MK. 2014. Fish behavioral types and their ecological consequences. Can J Fish Aquat Sci 71: 927-944.

Milinkovitch T, Ndiaye A, Sanchez W, Le Floch S, Thomas-Guyon H. 2011. Liver antioxidant and plasmatic immune responses in juvenile golden grey mullet (Liza aurata) exposed to dispersed crude oil. Aquat Tox 101: 155-164.

Milinkovitch T, Lucas J, Le Floch S, Thomas-Guyon H, Lefrançois C. 2012. Effect of dispersed crude oil exposure upon the aerobic metabolic scope in juvenile golden grey mullet (Liza aurata). Mar Poll Bull 64: 865-871.

Moles A, Rice S, Norcross BL. 1994. Non-avoidance of hydrocarbon laden sediments by juvenile flatfishes. Neth J Sea Res 32: 361-367.

Morrow JE. 1973. Oil-induced mortalities in juvenile coho and sockeye salmon. J Mar Res 31: 135-143.

Rice SD. 1973. Toxicity and avoidance tests with Prudhoe Bay oil and pink salmon fry. Joint conference on prevention and control of oil spills, Washington, DC, American Petroleum Institute, pp 667-670.

This article is protected by copyright. All rights reserved 
Roy G, Vuillemin R, Guyomarch J. 2005. On-site determination of polynuclear aromatic hydrocarbons in seawater by stir bar sorptive extraction (SBSE) and thermal desorption GCMS. Talanta 66: 540-546.

Sprague B, Drury DE. 1969. Avoidance reactions of salmonid fish to representative pollutants. In: Jenkins SH, ed, Advances In water pollution research, Pergamon Press, New York, USA, pp 169-179.

Summerfelt RC, Lewis WM. 1967. Repulsion of green sunfish by certain chemicals. J Water Pollut Control Fed 39: 2030-2038.

Sundt RC, Ruus A, Jonsson H, Skarphéðinsdóttir H, Meier S, Grung M, Beyer J, Pampanin, D.M. 2012. Biomarker responses in Atlantic cod (Gadus morhua) exposed to produced water from a North Sea oil field: Laboratory and field assessments. Mar Poll Bull 64: 144-152. Tierney KB, Baldwin BH, Hara TJ, Ross PS, Scholz NL, Kennedy CJ. 2010. Olfactory toxicity in fishes. Aquat Tox 96: 2-26.

Wannamaker CM, Rice JA. 2000. Effects of hypoxia on movements and behavior of selected estuarine organisms from the southeastern United States. J Exp Mar Biol Ecol 249: 145-163. Ward AJW, Krause J. 2001. Body length assortative shoaling in the European minnow, Phoxinus phoxinus. Anim Behav 62: 617-621.

This article is protected by copyright. All rights reserved 
Fig.1. A \& B: Schematic representations of the experimental set up. C: top view of the working arena where red and yellow dies are used to visualize the sharpness of lateral separation between the two flows as well as the shape of the leading edge. 1: Steel grids. 2: Honeycomb flow straighteners. 3: water mixing sections. 4: Head column with aeration. 5: Flowmeters.

Fig. 2 Percentage of time spent in the side of the choice box in which treated (WSF low, $\mathrm{WSF}_{\text {medium }}$ and $\mathrm{WSF}_{\text {high}}$ ) or untreated water (control) was introduced at Time 0 . Asterisks above bars indicate a significant difference from a 50\% null expectation.

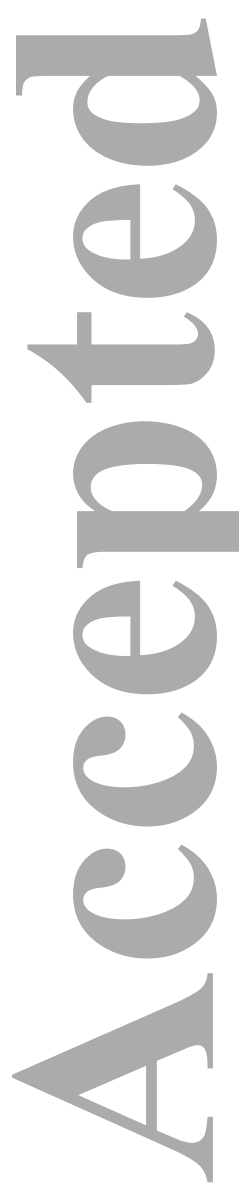

This article is protected by copyright. All rights reserved 
Table 1 Concentration (mean \pm SEM; ng $\mathrm{L}^{-1}$ ) of parents and alkylated PAH in the WSF stock solution ( $\mathrm{n}=3)$ and in the samples taken in the contaminated flow following the various experimental trials $(\mathrm{n}=20)$. “< “ indicates values below the given detection limit.

\begin{tabular}{|c|c|c|c|c|c|}
\hline Compound & Control & WSFlow & WSF medium & WSFhigh & WSF $_{\text {stock }}$ \\
\hline Benzothiophene & $<0.7$ & $4.7 \pm 0.3$ & $8.0 \pm 0.3$ & $12.9 \pm 0.9$ & $29.0 \pm 12.8$ \\
\hline C1-Benzothiophene & $<0.7$ & $66.0 \pm 33.1$ & $84.4 \pm 43.8$ & $167.8 \pm 40.3$ & $949.5 \pm 599.3$ \\
\hline C2-Benzothiophene & & & & $1124.3 \pm$ & \\
\hline \multirow{3}{*}{ C3-Benzothiophene } & $<0.7$ & $357.7 \pm 33$ & $765.0 \pm 88.2$ & 397.8 & $7181 \pm 4054.4$ \\
\hline & & & & & $17248.0 \pm$ \\
\hline & $<0.7$ & $801.8 \pm 119.8$ & $1875.3 \pm 330.7$ & $2717.2 \pm 1331$ & 2050 \\
\hline Naphthalene & $<2.6$ & $10.7 \pm 0.7$ & $19.5 \pm 1.5$ & $27.1 \pm 6.6$ & $171.7 \pm 101.6$ \\
\hline C1-naphthalene & $<2.6$ & $153.3 \pm 19.7$ & $333.8 \pm 35.9$ & $572.1 \pm 67.4$ & $2164.0 \pm 602.8$ \\
\hline C2-naphthalene & $<2.6$ & $1115.8 \pm 172.3$ & $2477.6 \pm 350.9$ & $4675.1 \pm 1567$ & $26174 \pm 15431$ \\
\hline \multirow[t]{2}{*}{ C3-naphthalene } & & & & & $23043.6 \pm$ \\
\hline & $<2.6$ & $1066.5 \pm 206$ & $2510.4 \pm 416.6$ & $4708 \pm 2023.9$ & 2588 \\
\hline Biphenyl & $<3.3$ & $4.3 \pm 0.4$ & $9.4 \pm 0.8$ & $36.7 \pm 11.5$ & $102.3 \pm 43.1$ \\
\hline Acenaphthylene & $0.7 \pm 0.2$ & $<0.5$ & $<0.5$ & $<0.5$ & $0.6 \pm 0.2$ \\
\hline Acenaphthene & $<0.7$ & $1.6 \pm 0.1$ & $4.2 \pm 0.1$ & $11.3 \pm 1.6$ & $44.4 \pm 20.9$ \\
\hline Fluorene & $<1$ & $8.8 \pm 0.6$ & $22.6 \pm 0.8$ & $74.2 \pm 8.4$ & $222.9 \pm 0.4$ \\
\hline C1-Fluorene & $<1$ & $12.5 \pm 1.2$ & $33.3 \pm 1$ & $76.3 \pm 7$ & $302.1 \pm 89.6$ \\
\hline C2-Fluorene & $<1$ & $16.1 \pm 2.5$ & $43.5 \pm 2.3$ & $72.8 \pm 14.6$ & $354.2 \pm 119.1$ \\
\hline C3-Fluorene & $<1$ & $10.4 \pm 1.4$ & $30.6 \pm 2.2$ & $49.4 \pm 10.1$ & $343.3 \pm 133.9$ \\
\hline Phenanthrene & $<3.1$ & $5.4 \pm 1$ & $16.7 \pm 2.4$ & $100.4 \pm 47.1$ & $202.2 \pm 49.6$ \\
\hline Anthracene & $<0.5$ & $<0.5$ & $<0.5$ & $<0.5$ & $2.2 \pm 2.2$ \\
\hline $\mathrm{C} 1$ & & & & & \\
\hline $\begin{array}{l}\text { phenanthrene/anthracene } \\
\text { C2 }\end{array}$ & $<3.1$ & $8.5 \pm 1.9$ & $23.5 \pm 1$ & $44.3 \pm 2.5$ & $213.0 \pm 63.6$ \\
\hline phenanthrene/anthracene & $<3.1$ & $5.1 \pm 0.7$ & $15.0 \pm 0.5$ & $19.0 \pm 0.8$ & $135.5 \pm 76.7$ \\
\hline C3-Dibenzothiophene & $<3.1$ & $<3.1$ & $9.1 \pm 0.5$ & $16.6 \pm 5.3$ & $72.8 \pm 14.2$ \\
\hline Dibenzothiophene & $<0.5$ & $25.8 \pm 0.9$ & $63.4 \pm 3.5$ & $158.3 \pm 18.5$ & $582.6 \pm 4.1$ \\
\hline C1-Dibenzothiophene & $<0.5$ & $41.0 \pm 2.5$ & $118.9 \pm 0.7$ & $173.9 \pm 4.3$ & $837.8 \pm 270.2$ \\
\hline C2-Dibenzothiophene & $<0.5$ & $22.7 \pm 1.7$ & $54.9 \pm 4$ & $58.6 \pm 11.1$ & $430.2 \pm 266.4$ \\
\hline C3-Dibenzothiophene & $<0.5$ & $8.0 \pm 0.4$ & $18.7 \pm 3.4$ & $28.7 \pm 8.9$ & $151.2 \pm 106.3$ \\
\hline Fluoranthene & $<0.6$ & $<0.6$ & $<0.6$ & $<0.6$ & $16.3 \pm 15.2$ \\
\hline Pyrene & $<0.5$ & $<0.5$ & $<0.5$ & $<0.5$ & $1.9 \pm 0.2$ \\
\hline C1-Fluoranthenes/Pyrenes & $<0.6$ & $<0.6$ & $<0.6$ & $<0.6$ & $8.3 \pm 2.2$ \\
\hline C2-Fluoranthenes/Pyrenes & $<0.6$ & $<0.6$ & $<0.6$ & $<0.6$ & $<0.6$ \\
\hline C3-Fluoranthenes/Pyrenes & $<0.6$ & $<0.6$ & $<0.6$ & $<0.6$ & $<0.6$ \\
\hline Benzo[a]anthracene & $<0.5$ & $<0.5$ & $<0.5$ & $<0.5$ & $1.8 \pm 0.9$ \\
\hline Chrysene & $1.2 \pm 0.2$ & $0.52 \pm 2.4$ & $1.6 \pm 0.4$ & $2.57 \pm 2.9$ & $9.7 \pm 2.2$ \\
\hline C1-Chrysenes & $<0.5$ & $<0.5$ & $<0.5$ & $<0.5$ & $<0.5$ \\
\hline C2-Chrysenes & $<0.5$ & $<0.5$ & $<0.5$ & $<0.5$ & $<0.5$ \\
\hline C3-Chrysenes & $<0.5$ & $<0.5$ & $<0.5$ & $<0.5$ & $<0.5$ \\
\hline Benzo $[\mathrm{b}+\mathrm{k}]$ fluoranthene & $2.8 \pm 1.3$ & $0.58 \pm 0.8$ & $1.9 \pm 1.6$ & $2.5 \pm 1.5$ & $12.0 \pm 14.8$ \\
\hline Benzo[e]pyrene & $1.9 \pm 1.9$ & $<0.5$ & $1.1 \pm 0.3$ & $3.08 \pm 1.3$ & $14.8 \pm 16.1$ \\
\hline Benzo[a]pyrene & $<0.5$ & $<0.5$ & $<0.5$ & $<0.5$ & $2.8 \pm 3.3$ \\
\hline Perylene & $<0.5$ & $<0.5$ & $<0.5$ & $<0.5$ & $2.6 \pm 3$ \\
\hline
\end{tabular}

This article is protected by copyright. All rights reserved 
Indeno(1,2,3-cd)pyrene

Dibenzo(a,h)anthracene

Benzo(g,h,i)perylene

Total PAH concentration
$<3.6$

$<4.8$

$<3.7$

6.6
$<3.6$

$<4.8$

$<3.7$

3748.2
$<3.6$

$<4.8$

$<3.7$

8542.4
$<3.6$

$<4,8$

$<3.7$

14935.7
$5.7 \pm 3$

$5.3 \pm$

$6.1 \pm 3.3$
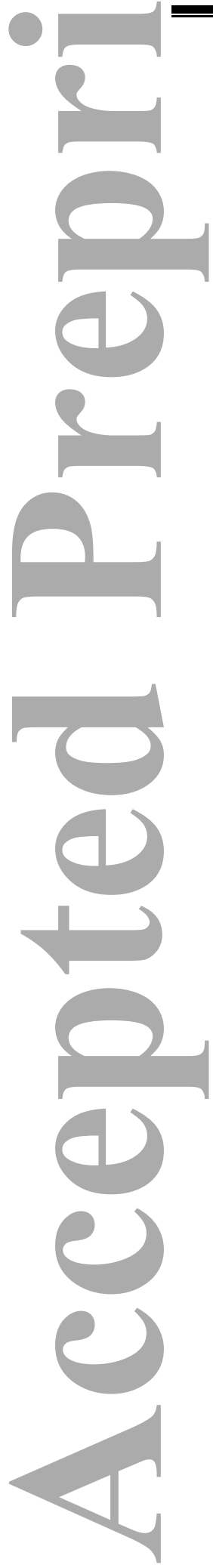

This article is protected by copyright. All rights reserved 


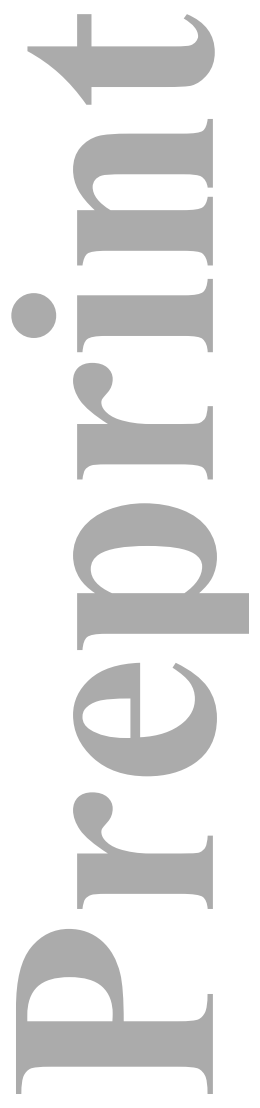

Figure 1

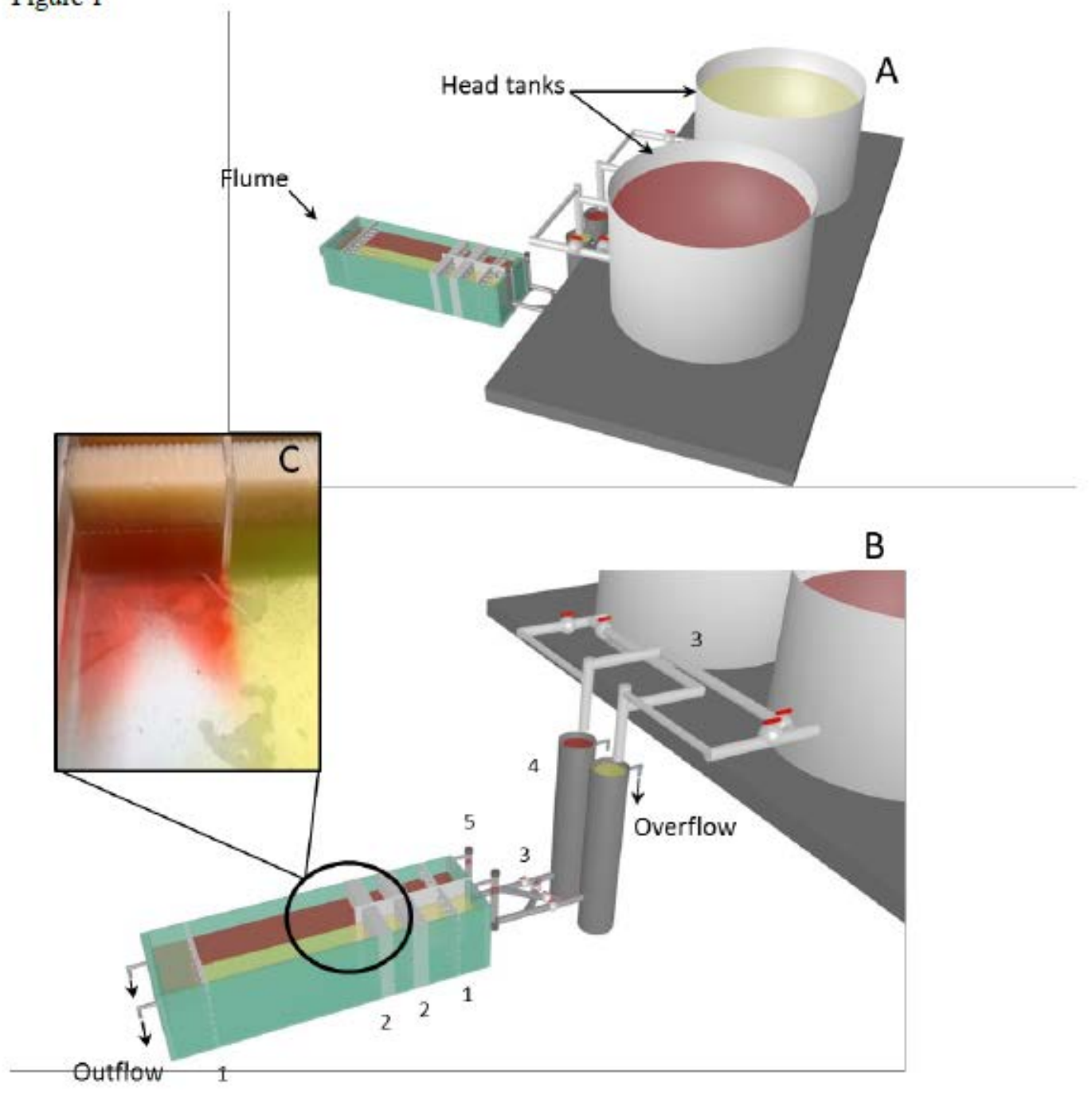

This article is protected by copyright. All rights reserved 
